\title{
Down Time Analysis of Dry Toner Based Digital Printing
}

\author{
Bijender, Vikram, Dhirender
}

\begin{abstract}
Digital is better than offset printing process as it imparts zero make-ready wastage. It also supports variable data printing advantages. Machine downtime of Konica Minolta C1085 and Richo pro 8100se digital press was analyzed in local market. The results indicated that white area on print matter, blank page, paper jam, paper curl, paper skew, wrinkle and creasing, print rub-off, miss feed, blur image, horizontal line, ink drop out, technical faults, custom paper, press room temperature, roller track, paper swing, paper moisture, registration, maintenance are the major issues contributed into downtime digital printing.
\end{abstract}

\section{INTRODUCTION}

Digital printing is a printing strategy utilizing computerized or electronic records from a PC or other advanced capacity gadget as a source. This advanced printing does not depend on a press plate to convey the picture and furthermore does not require any setup sheets. Because of lower creation costs, advanced printing has supplanted lithography in an extensive variety of business sectors. Although make ready wastage is negligible in digital printing, yet a lot of factors are there which are responsible for downtime in dry toner based digital printing which are required to be explored.

\section{RESEARCH OBJECTIVES}

Xerographic printing has become popular printing process to print on short run substrates with personalized benefits. Although there is negligible make-ready time and wastage occurring in xerographic printing, yet productivity, regular maintenance and machine reliability are issue of wide concern among most of printers.

The objective of present research project is:

1. To find out various factors which enhance downtime in dry toner production based xerographic printing presses.

2. To suggest solutions to enhance productivity \& reduce down time in dry toner production based xerographic printing presses.

\section{RESEARCH METHODOLOGY}

Materials use in this research- these types of paper used which are given below

* Coated papers

* Uncoated papers

* Photo papers

* Matt papers

* Gloss papers

* Gumming papers

Methods - In every printing process three steps are discussprepress, press and post press but here in this research press area is only concerned to identify the breakdown activity of digital dry tonner electrophotography. In this press area we work on two digital dry tonner electro photography printing machinesKonica Minolta Bizhub press C1085 and Richo pro 8100se in organization of "Hisar Photostat, Hisar".

\section{DATA COLLECTION \&ANALYSIS}

4.1 Downtime of Konica Minolta Press 1085:-

Table No.1. Downtime minutes for various reasons

\begin{tabular}{|c|r|r|r|r|r|r|}
\hline & Warm & \multicolumn{1}{c|}{$\begin{array}{l}\text { Color } \\
\text { patches }\end{array}$} & $\begin{array}{l}\text { Blank } \\
\text { Page }\end{array}$ & $\begin{array}{l}\text { Paper } \\
\text { Jam }\end{array}$ & $\begin{array}{l}\text { Paper } \\
\text { Curl }\end{array}$ & $\begin{array}{l}\text { Paper } \\
\text { Skew }\end{array}$ \\
Creasing
\end{tabular}

Revised Manuscript Received on December 30, 2019.

* Correspondence Author

Bijender, Assistant Professor, Deptt. of Printing Technology, GJUS\&T, Hisar

Vikram,M. Tech. Scholar, Deptt. of Printing Technology, GJUS\&T, Hisar

Dhirender, Technical Officer, Uflex, Noida

(c) The Authors. Published by Blue Eyes Intelligence Engineering and Sciences Publication (BEIESP). This is an open access article under the CC BY-NC-ND license (http://creativecommons.org/licenses/by-nc-nd/4.0/) 


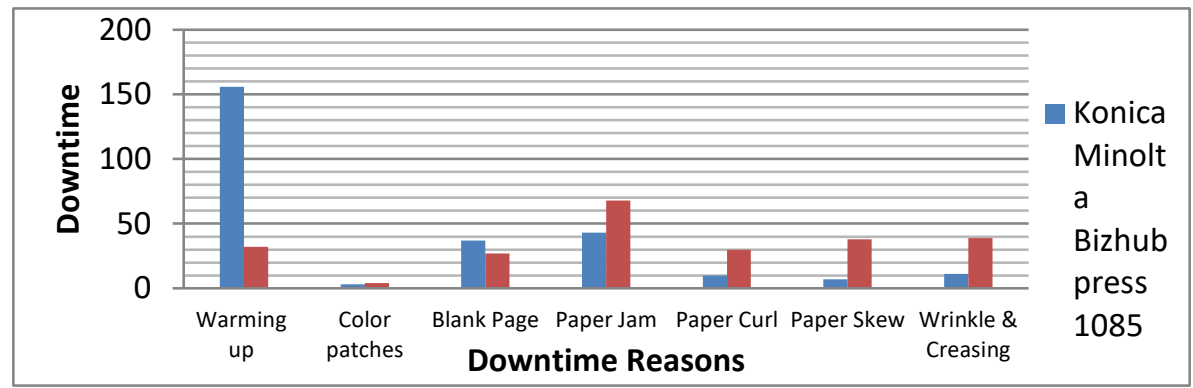

Chart. 1. Downtime minutes for various reasons

Table No.2. Downtime minutes for various reasons

\begin{tabular}{|c|r|r|r|r|r|r|}
\hline Machines & $\begin{array}{l}\text { Print } \\
\text { rub } \\
\text { off }\end{array}$ & $\begin{array}{l}\text { Miss- } \\
\text { feed }\end{array}$ & $\begin{array}{l}\text { Blur- } \\
\text { image }\end{array}$ & $\begin{array}{l}\text { Horizontal } \\
\text { line }\end{array}$ & $\begin{array}{l}\text { Ink } \\
\text { drop } \\
\text { out }\end{array}$ & $\begin{array}{l}\text { Technical } \\
\text { faults }\end{array}$ \\
\hline Konica Minolta Bizhub press 1085 & 2 & 35 & 5 & 6 \\
\hline Richo Pro 8100se & 4 & 55 & 20 & 101 \\
\hline Paper
\end{tabular}

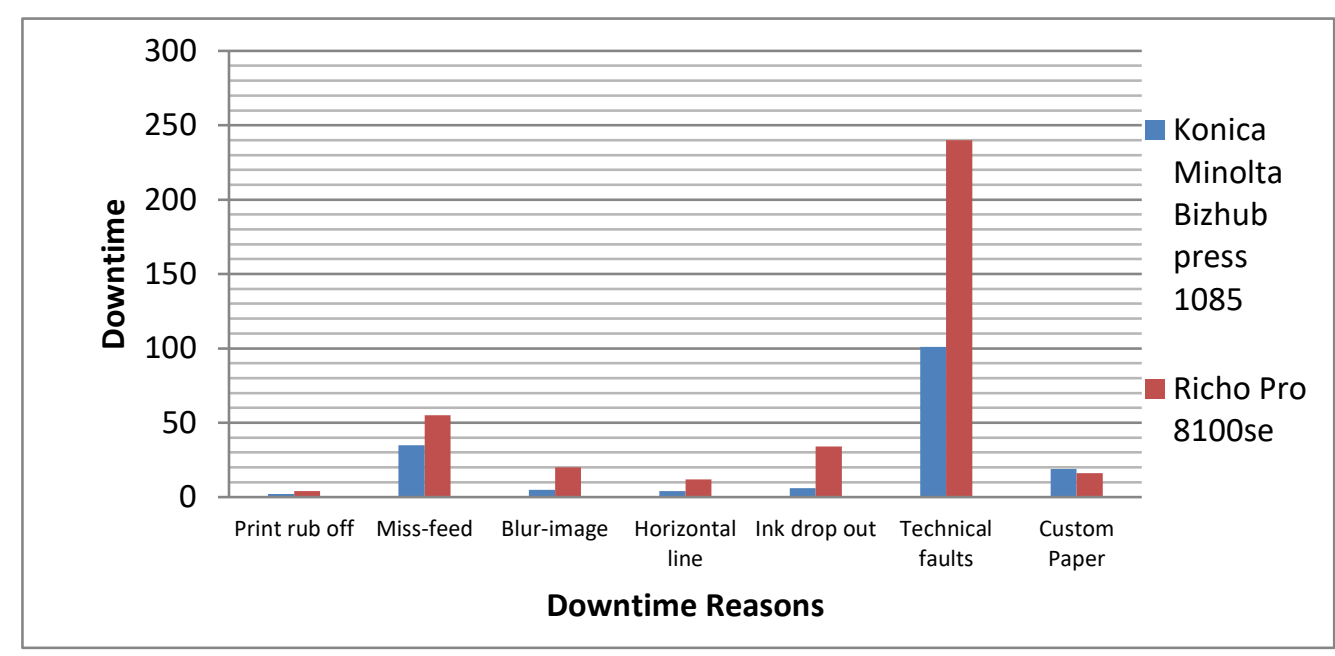

Chart. 2. Downtime minutes for various reasons

Table No.3. Downtime minutes for various reasons

\begin{tabular}{|c|c|c|c|c|c|c|c|}
\hline Machines & $\begin{array}{l}\text { Rough } \\
\text { paper }\end{array}$ & $\begin{array}{l}\text { Press } \\
\text { room } \\
\text { temp } \\
\text {. }\end{array}$ & $\begin{array}{l}\text { Rolle } \\
\mathrm{r} \\
\text { track }\end{array}$ & $\begin{array}{l}\text { Paper } \\
\text { swing }\end{array}$ & $\begin{array}{l}\text { Paper } \\
\text { moistur } \\
\mathrm{e}\end{array}$ & $\begin{array}{l}\text { Regist } \\
\text { ration }\end{array}$ & $\begin{array}{l}\text { Main } \\
\text { tenan } \\
\text { ce }\end{array}$ \\
\hline Konica Minolta Bizhub press 1085 & 5 & 23 & 15 & 24 & 32 & 34 & 60 \\
\hline Richo Pro 8100se & 15 & 5 & 4 & 38 & 43 & 52 & 15 \\
\hline
\end{tabular}




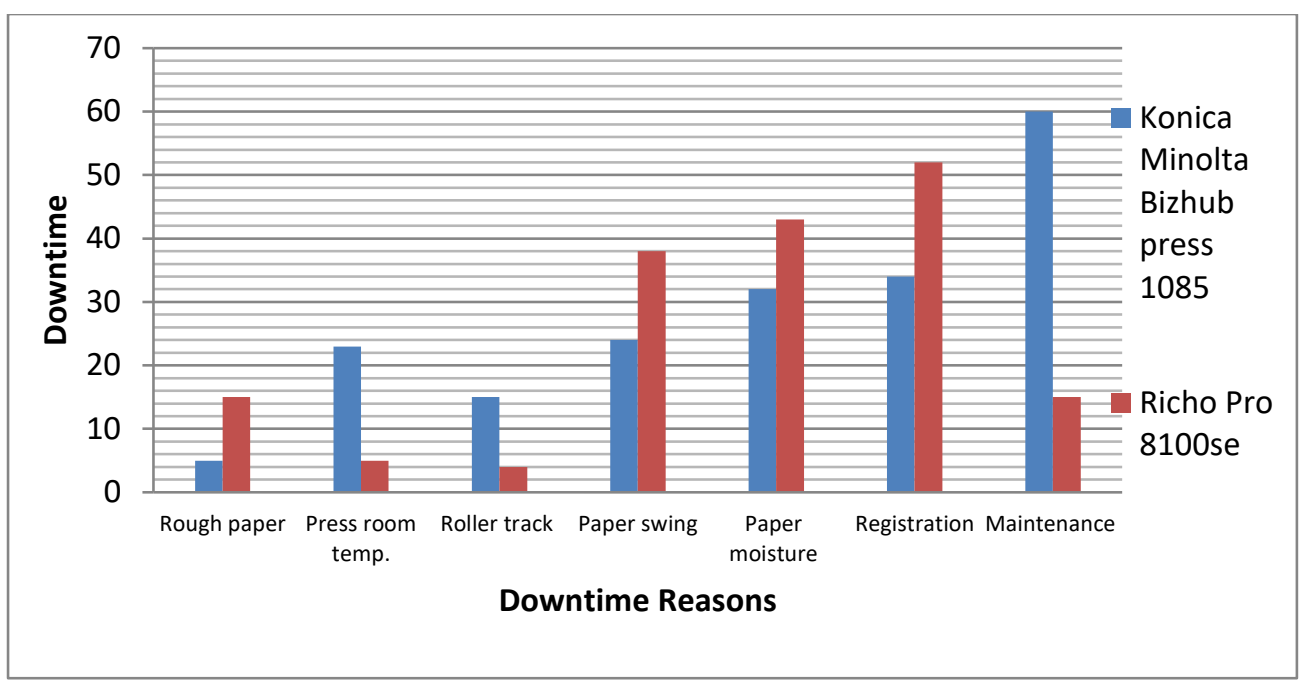

Chart. 3. Downtime minutes for various reasons

\section{RESULT \& DISCUSSION}

5.1 Factors responsible for increasing downtime in dry toner based printing Machine -Konica Minolta Bizhub press 1085

1. Adjustment \& Warming up.

2. Color patch of old job, Narrow media print last time, Adjustment Blank page back to original printed page

3. Registration out, dust in registration detector sensor, Missfeed of paper Paper jam

4. Paper curl, Paper curl in fusing unit, Moisture, Adjustment not suitable Paper

5. Page skew, Registration, Missfeed, Paper not suitable, Adjustment

6. Paper wrinkle creasing, Paper is not suitable.

7. Missfeed

8. Fusing belt change, fusing sensor cleaning, adjustment

9. Registration change, back image shift, duplex roller expiry

10. Technical fault, cleaning, charging developer, replacement part.

11. Paper cutting not proper, custom paper, printout from paper to roller

12. Registration out duplex print, dust on paper alignment tray, cleaning.

13. Paper is rough, jam in pickup roller, adjustment

14. Developer roller problem, paper slip, paper and machine specification not match

15. Tray to tight, paper setting is not proper, adjustment

16. Paper missfeed, pickup roller pressure inappropriate, paper tray setting

17. Fusing belt slip, maintenance of 1 hour actuator, replace belt

18. Temp. 30c humidity 32, dryness of machine, adjustment

19. Moisture of $3 \%$ paper, wrinkle and curl in paper.

20. Paper jam due to double sheet insert, moisture paper, gumming paper

21. Paper jam, toner smear, paper is not suitable for machine

22. Paper moisture, adjustment, paper shrink in fusing unit

23. Roller track create on the printed paper, paper jam, pressure roll not proper

24. Missfeed Paper, Tray setting not Proper, Adjustment

25. Print rub-off Fusing temp. low
26. Registration out due to feeding tray loose, Registration sensor not working

27. Paper jam, Not suitable climate condition

28. Paper jam because paper is too rough

29. Pickup roller pressure is not enough to transport the paper, paper swing in machine

30. Missfeed indication, Cleaning of paper delivery unit sensors

31. Blur image, ink drop out random place, paper specification not match to machine.

32. Horizontal line in print area, senor not working, calibration of senor require

33. Wrinkle and crease Machine functional Part specification not match

5.2 Factors responsible for reduce productivity in dry toner based printing. Machine -Richo Pro 8100se

1. Adjustment \& Warming up.

2. Moisture content of paper, climate condition not suitable

3. Custom paper, paper missfeed

4. Missfeed to pickup roller, missfeed to duplex plate paper away from sensor

5. Matter skew, registration out duplex matter

6. Double sheet detector off, more than 2 sheets block to pickup roller

7. Paper tray too tight, missfeed of paper

8. Substrate missfeed, paper tray loose, registration problem

9. Missfeed indication of sensor, cleaning required infeed sensor.

10. Paper transport roller problem, pressure of roller is improper, paper setting

11. Blur Image, drop out of ink bond, paper specification not match to machine.

12. Unwanted ink particle on paper, paper jam due to missfeed, adjustment.

13. Paper curl and shrink, heating setting of fusing unit, paper moisture problem.

14. Paper jam, paper specification not matches to machine.

15. Repeating image unwanted matter, cleaning of machine internal part.

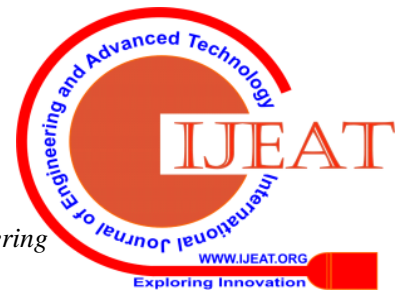


16. Missfeed of paper, paper tray is too tight, tray setting required.

17. Light print of whole page, toner low, adjustment.

18. Tire or roller impression on paper, roller presser is tight, change setting

19. Toner smears in print page, fusing unit temp setting.

20. Paper jams, missfeed of paper, machine internal cleaning required.

21. Wrinkle and creases, machine functional part specification not match

22. Toner smears on some place on paper, fusing unit temp setting

23. Paper jam due to dulex plate sensor is not working, adjustment.

24. Unwanted image print on image area, last time narrow paper print.

25. Moisture content of paper, paper specification not match to machine.

26. Missfeed of paper, not proper jogging and knocking, adjustment.

27. White area on print matter, paper specification not matches to machine.

28. Horizontal line on printed page, sensor calibrator not working, cleaning

29. Blank paper back to original, automatic double sheet is off.

30. Page skew, moisture of paper, dry out in fusing unit.

31. Missfeed paper, paper curl due to extra moisture.

32. Paper swing in transport roller, pressure of roller improper.

33. Paper tray is too tight, paper jam in pickup roller, adjustment

34. Wrinkle and crease, paper jam, turn part block the machine functional parts.

35. Paper jam, climate condition is not suitable, adjustment

36. Paper Curl and shrink, heating setting problem, Adjustment.

37. Print Smear or rub off, heating is not proper, Adjustment

\subsection{Controlling factors responsible for breakdown} in dry tonner based digital printing

5.3.1 Adjustment \& Warming up- In this research period, downtime is created by this issue is 156 minutes as shown in chart-1.Adjustment \& Warming up is necessary part of digital dry tonner printing. In this time period machine calibrate their automatic functional parts of machine like ADF, color profile, sensor etc. but in some cases, machine also take unwanted adjustment behind this main reason is inappropriate climate condition. If machine warming up time is extended from 1 mint in one time, tell this problem to machine supplier. If maintenance is due, install maintenance kit and ADF kit.

5.3.2 Color patch of old job- It is less reasonable issue of machine down time during research period 3-5 minutes are taken by machine as shown in chart-1. Thisproblem may occur after clearance of last jam in machine and narrow substrate is use for print. Properly clean machine fusing unit and functional parts of machine and print some pages to see problem. Generally, itis corrected itself. Machine sensors also can be recalibrated for the same.
5.3.3 Blank page back to original printed page or Double sheets- In this issue, downtime created is 37 minutes as shown in chart-1. This problem may occur only when double sheet detector sensor is off or sensor is covered with dust. Other reason of this is moisture content of paper and gumming sheets. Solution is clean the machine functional parts with cotton cloth and remove the dust of sensors and checkout sensor is active. After that problem is correct it and otherwise substrate may be change. If maintenance is due install maintenance kit and calibrate the scanners.

5.3.4 Registration out- Here, downtime create by this issue is 52 minutes as shown in chart-3. This problem may occur in digital printing then we print duplex print job. Main reasons of this problem are loose of infeed tray, manual machine cutting paper and registration sensors are not working or sensor covered with dust. Solution checkouts the paper is on right angle, checkout the sensor is proper calibrated and proper adjustment of infeed try of machine. Checkout if maintenance due and install maintenance kit.

5.3.5 Paper jam-In this research time period, downtime create by this issue is max. 68minutes as shown in chart-1. Main reasons of paper jam is that moisture content of paper, paper specification not match to machine, paper is not on right angle, paper infeed try is too loose or tight, turn part of paper block the machine functional part and rough paper. Solution change the paper if specifications not match to machine, checkout the moisture content of paper before printing, and follow the direction of guide manual before loading paper in machine and use machine specification match papers.

5.3.6 Paper curl- In this research time period the downtime create by this issue is 30 minutes as shown in chart-1. Main reasons of this problem are moisture content of paper, heating temp. of fusing unit is higher and paper specification not match to machine. Paper should be lightweight and smooth. Solution turns the direction of paper in tray and rotating paper to 180 Degree. Change the paper if specification not matches to machine. Check that machine functional parts specification match to paper. If paper is light weight and smooth change machine function parts setting according to paper.

5.3.7 Paper skew- In this research period downtime create by this issue is 38 minutes as shown in chart-1. This problem may occur then turn parts of paper of last jam blocks the machine functional part, paper specification not match to machine. Solution checkout no any kind of turn part of paper inside the machine functional parts, turn paper direction in tray and try to rotate the paper 180 degree, make sure that paper specification match to machine, checkout the paper tray configuration match to paper.

5.3.8 Paper wrinkle creasing- In this research period downtime create by this issue is 39 minutes as shown in chart-1. Reasons of this problem rough paper, turn part of paper block machine functional parts, paper moisture content and machine configuration is not match to machine. Solution of this problem paper specification should match to machine, paper rotate to 180 degree in machine tray, machine configuration should set according to paper, verify that while clearing the jam there is 
5.3.9 Print-rub off-It is less reasonable issue of downtime in our research work because 2-4 minutes waste as shown in chart-2.This problem may come then fusing temperature is inappropriate, the paper specification not matches to machine, machine specification not match to paper. Solution machine configuration should match to paper, paper specification should match to machine, and fusing unit temp is set according paper types.

5.3.10 Missfeed-In this research period downtime create by this issue is 55 minutes as shown in chart-2. Missfeed is main reason of breakdown in digital dry toner printing. There are many issue of wrong feed/missfeed. Rough papers, moisture content of paper, light weight paper, turn part paper block machine functional area, machine sensor cover with dust, machine configuration not match to paper, paper specification not match machine, paper swing in machine functional roller. Solution verifies that no any kind of turn part in functional parts of machine, paper and machine specification should match to each other, Change the paper if specification not matches and checkout machine maintenance is required. Make sure that environment specification match to machine.

5.3.11 Blur image- In this research period downtime create by this issue is 20 minutes as shown in chart- 2 . Thisproblem of breakdown may occur then fusing temp of machine not suitable for fusing the ink density on paper, if paper quality not matches to machine, paper and machine configuration not matches to each other, environment specification not matches to machine. Solution verifies that paper quality match to machine, turn paper direction in machine tray, print some papers to see defect correct itself, decrease tonner density, paper and machine configuration matches to each other.

5.3.12 Horizontal line- In this research period downtime create by this issue is 12 minutes. This problem occurs then maintenance is due. During this problem occurs an operator should clean machine internal part like clean machine fusing unit and ADF. If this problem occurs show the machine supplier. If machine maintenance is due install the maintenance kit and ADF kit. Calibrate the machine scanners.

5.3.13 Toner Smear- One reason of this problem is paper and machine configuration doesn't matches. If paper is too rough this breakdown may arise. This problem is technical problem may occur then technical fault arise in machine like fusing unit expiry. If this problem may occur tell about this machine supplier. If maintenance due install maintenance kit. Calibrate the sensors.

5.3.14 Ink drop-out-In this research period downtime creates by this issue is 34 minutes as shown in chart- 2 . Thisproblem may arise then paper is too rough. Environment specification not matches to machine. Paper and machine specification not matches to each other. Solution paper should be smooth. And paper and machine specification should match to each other. And environment specification should be standard according to machine specification. Paper should be smooth. If paper is rough tonner easily rough off open machine configure and select paper variation and fusing temperature from high1 to high 2 according to paper specification.
5.3.15 Light print- paper is not suitable for machine. Otherwise toner cartridge not fully installs, low tonner level, paper machine configuration not matches with each other, environment condition or specification not suitable. Paper should be change, if maintenance is pending install maintenance kit. Calibrate the sensors. Print some paper if problem correct itself.

5.3.16 Repeated image unwanted matter- this type defect may arise then be print large format print on narrow paper or manual cutting machine paper. Then extra toner stacks of on transfer roller which create unwanted repeated image on new print job, and paper specification not match to machine. Solution cleans the machine functional area after paper block machine functional areas; clean all rollers with cotton cloth. Paper specification should match machine. If machine maintenance is due install the maintenance kit. Print few pages to check out if problem correct itself.

5.3.17 Vertical line- Reason of this defect is paper specification which does not match to machine. It may be due to lack of machine maintenance. Print some page if defect clear itself, install maintenance kit, sensor calibration. Vertical in print show that ADF is covered with dirty, should clean ADF and calibrate the sensors. If paper specification not matches then change the paper.

5.3.18 Unwanted ink particle- this defect indicates that paper and machine specification not matches each other, climate condition is not suitable or machine maintenance is due or ADF is covered with dust. Install machine maintenance kit, clean machine ADF, clean daily with cotton cloth, paper and machine specification should match with each other.

5.3.19 White area on print matter- This defect may arise then paper is rough, machine specification not match with paper, dust particles in fusing unit and climate condition not suitable or machine maintenance is due. Solution paper and machine specification should match with each other. Climate condition should be 25-30 degree temperature and 30-45\% humidity. Install machine maintenance kit, print some pages to check out and the defect is corrected himself.

5.4 Most vulnerable Factors causing machine downtime: - By analyzing the data of December, January and February month it was quite evident that stylus fracture and machine hanging are the most frequent occurring downtime on Dry toner based electrophotography. Warming up, blank papers, paper jam, mis-feed, paper moisture and technical fault are most frequent reasons of downtime in electro-photography as shown in table 1, 2, 3 and chart1,2,3. Rough paper, press room temperature, custom paper, ink drop out, paper skew, paper curls roller track, print rub-off, white area on print matter, horizontal line and blur image less frequent reason for downtime from overall data. These problems depend upon operator skill and experience. 


\section{CONCLUSION}

- White area on print matter, Blank page, paper jam, paper curl, paper skew, wrinkle \& creasing, print rub-off, miss-feed, Blur image, horizontal line, ink drop out, technical faults, custom paper, rough paper, press room temp., roller track, paper swing, paper moisture, registration, maintenance are the main factors which enhance machine downtime dry toner based electrophotography.

- $\quad$ Productivity can be further optimized using proper maintenance technique such as daily dust cleaning of machine, internal and external weekly cleaning of machine internal parts, monthly service of machine and replacing the parts of machine before expiry dates.

\section{REFERENCES}

1. Ahmed H. Eid, Brian E. Cooper, Mohamed N. Ahmed, Mohamed N. Ahmed (Characterization of Ghosting Defects in Electropotography Printers )

2. Ahmed, H. EidMohamed, N. AhmedBrian, E. Cooper, Edward E. Rippetoe (Characterization of Electropotography Print Artifacts: Banding, Jitter, and Ghosting)

3. David E. Rumph, Eric S. Nickell, Robert M. Coleman (Anamorphic object optimized function application for printer defect precompensation)

4. Lu Chen,Jason Kirkwood,Mohan Mahadevan,James A. Smith,Lisheng Gao,Junqing Huang,Tao Luo,Richard Wallingford (Systems and methods for detecting image quality defects)

5. TsuneakiKawanishi, Yasuki Mori, Koji Noguchi, Tsutomu Iimura (Electropotography process with magnetic brush development using semi conductive ferrite carriers)

6. Robert M. Coleman (Efficient identification of predicted printer defects for anamorphic pre-compensation)

7. John C. Briggs QEA, Inc Burlington, MA/USA Mike Murphy and Yichuan Pan Encad, Inc San Diego, CA/USA (Banding Characterization for Inkjet Printing)

8. C. Briggs, Eugene Hong and David Forrest QEA, Inc. Burlington, MA/USA (Analysis of Ghosting in XerographicJohn)

9. Ming-Kai Tse, David J. Forrest and Francis Y. Wong Quality Engineering Associates, Inc. Burlington, MA 01803 USA (Predicting Print Quality in Xerographic Using Electrostatic Charge Decay Measurements on Development Rollers)

10. RozáliaSzentgyörgyvölgyi, ÁkosBorbélyÓbuda University, RejtőSándor Faculty of Light Industry and Environmental Engineering, Budapest, Hungary(Quality of electropotography prints on foil substrates)

\section{AUTHOR PROFILE}

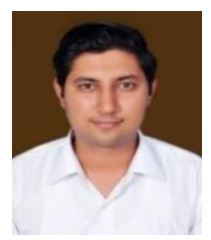

Bijender is gold medallist and renouned author in the field of Printing Technology. He is one of the rare printing teachers in India, who has got G7 expert certification from Idealliance, America. He is currently working as assistant professor in Department of Printing Technology, Guru Jambheshwar University of Science \& Technology, Hisar, Haryana, India. He is having more than 8 years experience of teaching as research in the field of printing technology.

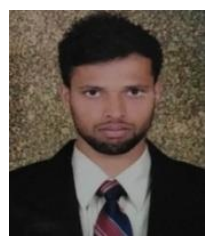

Vikram is pursuing his Master Degree in Printing Technology from Guru Jambheshwar University of Science \& technology, Hisar. This is my first research in Printing Industry. I have 45 Days training experince in Tample Packaging LTD. Sh. Bijender is my M-Tech Project Guide. I am also a athletic of Powerlifting and Bodybuilding. Bronze Madalist in District Powerlifting Hisar.

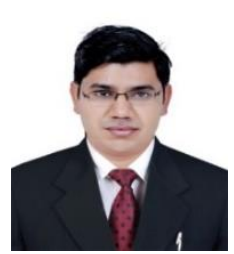

Dhirender is currently working as Technical Officer-Pre-press in Uflex Limited, Noida, UP, India. Uflex is the largest multinational flexible packaging industy of whole Asia. He is having unique expertise in Gravure printing industry with a lot of research and innovations he has carried out in the field of printing industry. $\mathrm{He}$ is having 10 years of experience and expertise in Printing Industry. 